\title{
Leisure Studies Association Annual Conference 2021. Leisure Identities, Health and Wellbeing: Conference Review
}

\author{
Catherine Phipps ${ }^{\mathrm{a} *}$
}

${ }^{a}$ Faculty of Sport, Health, and Social Sciences, Solent University, Southampton, UK

catherine.phipps@solent.ac.uk

The Leisure Studies Association Annual Conference 2021 brought together scholars and practitioners from several disciplines to discuss leisure, health, and wellness, and the significance of leisure in creating a more equitable world. Alongside these main themes, oral presentations related to other areas of leisure were also included. Across the three-day online conference, there were 70 presentations from delegates across sixteen countries. These presentations, plus the panel session and keynotes, made a significant contribution to the leisure studies field. The conference was successful in terms of sharing research and expertise, generating discussion, dialogue, and debate, and considering future research collaborations.

\section{KEYWORDS}

Leisure; health; wellbeing; tourism; sport

\section{ABSTRACT}

The Leisure Studies Association Annual Conference took place between the 6th and 8th July 2021, hosted virtually by the Faculty of Sport, Health, and Social Sciences at Solent University in the UK alongside the Leisure Studies Association. The conference asked a key question of scholars and practitioners across a range of disciplines: What role does leisure play in addressing "healthy" identities, for who, and for what purpose? In particular, the conference asked delegates to reconsider the role and significance of leisure in creating a social world based on social justice, equity, and equality. The conference included 70 presentations from delegates across sixteen countries, as well as three keynote presentations, a panel discussion, and a $Q+A$ session with the editors of the Leisure Studies Journal, the journal of the Leisure Studies Association. The conference therefore provided an opportunity to showcase global perspectives on leisure.

Throughout the conference, three keynotes took place. The first day began with an opening keynote by Professor Samantha King (Queen's University, Canada), titled "Of Companionship, Curfews and Conflict: Multispecies Leisure and Struggles for Justice in the Age of COVID-19", which explored animal-human relations, and set the context for understanding multispecies leisure during the pandemic (King, 2021). The second day started with an introductory keynote by Associate Professor Brad Millington (Brock University, Canada), titled "Leisure, Wearable Technology, and the Attention Economy", which considered online communication, consumerism, and the commodification of health, fitness, and wellness, with a focus on the interactive technology of fitness apps (Millington, 2021). On day three, a joint keynote by Dr Shamser Sinha (University of Suffolk, UK) and Professor Les Back (Goldsmiths, University of London, UK) took place, titled "Sociable Sociology: Dialogue, Ethics and Authorship in Qualitative Research". This presentation focussed on communication and 
narratives in qualitative studies, using research from young migrants to demonstrate this (Sinha \& Back, 2021). These keynotes provided broad perspectives on many aspects of leisure, including health, COVID-19, and the use of different methodologies, adding new insights to the field of leisure studies.

In addition to the keynote presentations, a panel discussion was included on day two, named "Equity, Inclusivity and Social Justice in Marginalised Leisure Communities". Past research has highlighted the prominence of leisure and health inequalities/constraints globally, impacted by a multitude of intersectional factors such as socio-economic status (Higgerson et al., 2018), gender (Codina \& Pestana, 2019), ethnicity (Karlis et al., 2020) and disability (Condie, 2021), amongst others. However, leisure also has the potential to promote social inclusion. In this discussion, invited speakers (Amy Woodford and Rhian Jones, Solent University, UK; Dr Paul Kitchin, Ulster University, UK; and Tiara Cash, Arizona State University, USA) outlined current projects they were involved in focussing on equity in leisure, including: an intervention aimed at increasing health and wellness literacy for women from low socio-economic and diverse ethnic backgrounds in Southampton, UK; reflections on working in disability sport in London and Belfast, outlining the organisational challenges of provision; and Equitable Mindfulness to increase our awareness of issues and identify areas in need of social change (Kitchin et al., 2021). The panel was useful to consider the challenges involved in projects (and how these can be overcome), methods used to analyse the impact of these projects, and how projects have been adapted in light of the COVID-19 pandemic.

Aside from keynotes and the panel discussion, several parallel sessions also took place. Two streams on the impact of COVID-19 on leisure practices were included in day one of the conference, which comprised presentations on walking as a leisure activity during lockdown (Platt, 2021; Sharp, 2021); home-based leisure (Lee, 2021); leisure, nature and wellness (Scarles, 2021); the impact of the pandemic on visually-impaired sportspeople (Powis \& MacBeth, 2021); and its impact on sport and gym spaces (Wellard, 2021). Other streams - such as "Leisure, Nature and the Outdoors" and "The Impact of Leisure on Social Connectedness" also included findings from studies on lockdown and pandemic leisure. These streams were a space to share findings which add to the emerging body of multi-disciplinary and inter-disciplinary research in this area (for instance Bowes et al., 2021; Ling, 2020; Soga et al., 2021; Spence et al., 2021).

The international nature of the conference was evident throughout, with global perspectives on leisure prominent. For instance, in a stream on children's and youth's leisure practices, the leisure constraints of children in Colombia were investigated (Diaz Hernandez, 2021). During the leisure and work session, work-leisure relationships were analysed during the COVID-19 lockdowns in China (Liu, 2021). One of the streams on gender relations included young people's place-making in rural northern Sweden (Gotfredsen, 2021), and the session on serious leisure included a presentation on homebrewing in South Korea (Pooley, 2021). Leisure practices and culture in Kazakhstan were also presented in the stream on leisure and tourism development (Kazmukhambetova, 2021), and the Pigtown festival in Baltimore, USA was critically analysed in a stream on festivals and events (Mowatt, 2021). The global nature of the conference was a key strength; much research on leisure is western-centric, and key leisure journals (such as the Leisure Studies Journal) aims to develop culturally-diverse understandings of leisure, and attract research about leisure in the Global South (Leisure Studies, 2021).

The conference, overall, was successful in creating an online space to connect and socialise with other researchers, share current research/expertise, generate dialogue, discussion, and debate, and consider future research collaborations. In summary, there were several important themes which derived from the conference. Firstly, wellness during the ongoing COVID-19 pandemic was 
prominent, including how leisure has been adapted, and how nature and green spaces have impacted our health and wellbeing. This is an emerging research area and the conference was therefore a space which significantly contributed to our understanding of wellness and COVID-19. Secondly, equity in leisure and wellness was central, fostering our understanding of various demographic groups, social inclusion, and wellbeing. This is vital to address calls for more inclusive leisure and wellness spaces and make strides towards health equity. The 2022 conference will take place using a hybrid format at Falmouth University, UK between July 12th to 14th, titled "In Pursuit of Leisure: Inequality, Storytelling and the Meanings of Place".

\section{Disclosure statement}

No potential conflict of interest was reported by the author(s).

\section{Notes on contributor}

Catherine Phipps is a Senior Lecturer in Sport and Physical Education at Solent University. She completed her PhD at the University of Greenwich in 2019, exploring LGBT+ inclusion in university sport. She was Chair of the Leisure Studies Association Annual Conference 2021, hosted by Solent University.

\section{ORCID}

Catherine Phipps http://orcid.org/0000-0003-0387-1218

\section{References}

Bowes, A., Lomax, L., \& Piasecki, J. (2021). A losing battle? Women's sport pre- and post-COVID-19. European Sport Management Quarterly, 21(3), 443-461. https://doi.org/10.1080/16184742.2021.1904267

Codina, N., \& Pestana, J. V. (2019). Time matters differently in leisure experience for men and women: Leisure dedication and time perspective. International Journal of Environmental Research and Public Health, 16(14), 1-11. https://doi.org/10.3390/ijerph16142513

Condie, G. A. (2021). Exploring the personal and social aspects of individuals with physical disabilities' leisure experiences: Experiencing leisure but as an individual person. Leisure Studies, 40(3), 363-377. https://doi.org/10.1080/02614367.2020.1843691

Diaz Hernandez, A. (2021, July 6-8). Children's leisure and leisure constraints in the informal settlements of Soacha (Colombia) [Paper presentation]. Leisure Studies Association Annual Conference, Southampton, UK.

Gotfredsen, A. (2021, July 6-8). Precarious leisure in a teenage wasteland? Intertwining discourses on responsibility and young people's place-making in rural northern Sweden [Paper presentation]. Leisure Studies Association Annual Conference, Southampton, UK.

Higgerson, J., Halliday, E., Ortiz-Nunez, A., Brown, R., \& Barr, B. (2018). Impact of free access to leisure facilities and community outreach on inequalities in physical activity: A quasi-experimental study. Journal of Epidemiology \& Community Health, 72(3), 252-258. https://doi.org/10.1136/jech2017-209882

Karlis, G., Stratas, A., Hamidi, W., Oey, J., \& Gravelle, F. (2020). Research on leisure and ethnicity: A review of two Canadian bilingual peer-reviewed journals from 2000 to today. Loisir et Société/Society and Leisure, 43(1), 70-79. https://doi.org/10.1080/07053436.2020.1727656 
Kazmukhambetova, G. (2021, July 6-8). Circular principles in the practice of leisure services for the formation of an holistic approach in the 'healthy' leisure culture of Kazakhstan [Paper presentation]. Leisure Studies Association Annual Conference, Southampton, UK.

King, S. (2021, July 6-8). Of companionship, curfews, and conflict: Multispecies leisure and struggles for justice in the age of COVID-19 [Keynote presentation]. Leisure Studies Association Annual Conference, Southampton, UK.

Kitchin, P., Cash, T., Jones, R., \& Woodford, A. (2021, July 6-8). Equity, inclusivity, and social justice in marginalised leisure communities [Panel discussion]. Leisure Studies Association Annual Conference, Southampton, UK.

Lee, K. (2021, July 6-8). Home climbing wall as a negotiation of the Covid-19 pandemic [Paper presentation]. Leisure Studies Association Annual Conference, Southampton, UK.

Leisure Studies. (2021). Aims and scope.

https://www.tandfonline.com/action/journallnformation?show=aimsScope\&journalCode=rlst20

Ling, P. (2020). Interpretation of leisure sports in the pandemic situation of COVID 19. World Leisure Journal, 62(4), 319-321. https://doi.org/10.1080/16078055.2020.1828786

Liu, H. (2021, July 6-8). A quest of balanced relationship between leisure and work among Chinese during the coronavirus lockdown [Paper presentation]. Leisure Studies Association Annual Conference, Southampton, UK.

Millington, B. (2021, July 6-8). Leisure, wearable technology, and the attention economy [Keynote presentation]. Leisure Studies Association Annual Conference, Southampton, UK.

Mowatt, R. A. (2021, July 6-8). The 'villainous looking negroes' of Pigtown and other 'crime' and public health myths of gentrification [Paper presentation]. Leisure Studies Association Annual Conference, Southampton, UK.

Platt, L. (2021, July 6-8). I never wanted to be an organiser. I just wanted to meet other mums: Walking through maternity leave in lockdown [Paper presentation]. Leisure Studies Association Annual Conference, Southampton, UK.

Pooley, A. (2021, July 6-8). Homebrewing as serious leisure: A sociolinguistic perspective [Paper presentation]. Leisure Studies Association Annual Conference, Southampton, UK.

Powis, B., \& MacBeth, J. (2021, July 6-8). Visually impaired peoples' experiences of outdoor running during the Covid-19 pandemic [Paper presentation]. Leisure Studies Association Annual Conference, Southampton, UK.

Scarles, C. (2021, July 6-8). Nature engagement and wellbeing during the Covid-19 pandemic: A qualitative photo-elicitation study [Paper presentation]. Leisure Studies Association Annual Conference, Southampton, UK.

Sharp, B. (2021, July 6-8). Beyond walking: The ritualistic nature of pandemic leisure [Paper presentation]. Leisure Studies Association Annual Conference, Southampton, UK.

Sinha, S., \& Back, L. (2021, July 6-8). Sociable sociology: Dialogue, ethics and authorship in qualitative research [Keynote presentation]. Leisure Studies Association Annual Conference, Southampton, UK. 
Soga, M., Evans, M. J., Tsuchiya, K., \& Fukano, Y. (2021). A room with a green view: The importance of nearby nature for mental health during the COVID-19 pandemic. Ecological Applications, 31(2), 110. https://doi.org/10.1002/eap.2248

Spence, J. C., Rhodes, R. E., McCurdy, A., Mangan, A., Hopkins, D., \& Mummery, W. K. (2021).

Determinants of physical activity among adults in the United Kingdom during the COVID-19 pandemic: The DUK-COVID study. British Journal of Health Psychology, 26(2), 588-605.

https://doi.org/10.1111/bjhp.12497

Wellard, I. (2021, July 6-8). Germ-free adolescents (and adults) in leisure activities: Reflecting upon the impact of a pandemic upon gym bodies and movement cultures [Paper presentation]. Leisure Studies Association Annual Conference, Southampton, UK. 